\title{
Competition - An Efficient Method to get Students Committed
}

\author{
Kalevi Hyyppä, Member, IEEE \\ EISLAB \\ Luleå University of Technology SE-971 87 Luleå, Sweden \\ e-mail: Kalevi.Hyyppa@1tu.se
}

\begin{abstract}
The Mechatronics course at Luleå University of Technology is divided into a traditional part with lectures, problem solving, lab exercises, and a project part. During 2002-2003 the project has been to design and build autonomous model race cars. A public race is arranged at the end of the course. The race track is an outdoor track. In year 2002 it was defined by a painted white line on asphalt. In 2003 it was defined by an electrical wire carrying $100 \mathrm{~mA}$ of current at $10 \mathrm{kHz}$ frequency. The students had to design and build sensors, amplifiers, filters and interface circuits for the onboard PIC16F876 microcontroller as well as some power electronics to control the drive $D C$-motor. The race is obviously extremely challenging for the students and as a result they spend much more time on the course than before.
\end{abstract}

\section{Introduction}

A first course in Mechatronics has been given at Luleå University of Technology for a few years. It is given in the last quarter of the students third year of studies. The course is worth 7.5 ECTS credit points. The students are expected to have taken at least one course in Electronics, Control theory and Programming, respectively, before the Mechatronics course. The students come from many different study programs meaning that their real knowledge in these subjects differs a lot.

The course is divided into a traditional part with lectures, problem solving, lab exercises, and a project part. The project part has had different contents over the years. During 2002-2003 the project has been to design and build autonomous model race cars. A public race is arranged at the end of the course. The race track is an outdoor track. In year 2002 it was defined by a painted white line on asphalt. In 2003 it was defined by an electrical wire carrying 100 $\mathrm{mA}$ of current at $10 \mathrm{kHz}$ frequency. The students had to design and build sensors, amplifiers, filters and interface cir- cuits for the onboard PIC16F876 microcontroller as well as some power electronics to control the drive DC-motor.

The race is obviously extremely challenging for the students and as a result they spend much more time on the course than before. This is the key to deep learning as was stated already by R.W. Tyler in 1949 [1]:

Learning takes place through the active behavior of the student: it is what he does that he learns, not what the teacher does.

The same fact is the basic idea in Biggs well-known book [2].

Mechatronics courses are given at several Swedish universities. Most of them include a project part and a few also have some kind of competition at the end of the course.

NATCAR [3] is probably the biggest educational mechatronics race event on the international scene. Five Californian universities and Oklahoma State University participate. The following can be read on the NATCAR home page [3]:

The objective of the competition is to design and construct an autonomous race car that can negotiate a preset course in the shortest time possible. The course is marked by 1-inch-wide white floor tape (shiny vinyl tape) on a darkcolored background (carpet). In addition, there is a wire under the tape and the wire is driven with a $75 \mathrm{kHz}$ sinusoidal signal (100 mA rms +/- 10\%).

The NATCAR race cars are built on standard off-theshelf $1 / 10$ scale radio controlled electric cars. When the race reported in this paper was defined the NATCAR event was not known to the author. The rules for the two races are surprisingly similar.

Another nice mechatronics competition is arranged by Technical University of Denmark [4].

Mechatronics courses with some kind of competition included are reported in $[5,6,7,8,9,10]$. Mechatronics education, in general, is treated in $[11,12,13]$. 


\section{Course structure}

\subsection{Lectures}

There are 8 lectures in the course covering part of the course curriculum. The course topics are shown in Table 1. Entries marked with a "-" are not lectured. The topics follow roughly the structure in the used textbook [14].

\begin{tabular}{cl}
\hline \hline$\#$ & Topic \\
\hline 1 & $\begin{array}{l}\text { Introduction, electric circuits and components, } \\
\text { grounding, electrical interference }\end{array}$ \\
2 & Diodes and transistors \\
3 & Operational amplifiers \\
- & Digital circuits \\
- & Microcontrollers, the PIC processor \\
- & Data acquisition \\
4 & Actuators \\
$5-8$ & Available time to discuss project related issues \\
\hline
\end{tabular}

Table 1. Lectures

\subsection{Problem solving}

Problem solving is one of the corner stones for deep learning. However, the course economy does not allow supervised problem solving. The students are instead encouraged to solve a given list of 29 problems from the textbook. Solutions to the problems are published on the course home page during the course.

\subsection{Lab exercises}

There are 5 lab exercises in the course. The topics are shown in Table 2. Four hours are scheduled for the first lab exercise and two hours for the others.

\begin{tabular}{ll}
\hline \hline$\#$ & Topic \\
\hline 1 & The bipolar transistor used as a switch \\
2 & A band-pass filter realization using one op-amp \\
3 & A combinational logic circuit with TTL gates \\
4 & A permanent magnet DC-motor with driver \\
5 & A stepper motor with driver
\end{tabular}

Table 2. Lab exercises

All lab exercises require extensive preparations through simulations. The simulations are checked by the lab supervisor before the students are allowed to begin. The software package OrCAD with the simulator PSpice from $\mathrm{Ca}-$ dence is used for the simulations. Although this software is mainly targeted for simulation of electronic circuits it is also well suited for mechatronic simulations. PSpice allows modelling of any physical property which can be described mathematically. Moment of inertia of a DC motor is a typical example.

\subsection{Project part}

In 2003 the project part of the Mechatronics course was described like this on the course home page:

You will modify an electrically driven model car to become an autonomous mobile robot. It should be equipped with magnetic field sensors to enable it to follow a race track defined by a wire carrying AC-current. The signals from the magnetic field sensors should after amplification, filtering and possible further processing be feed to the ADC of a PIC processor. The processor should be programmed to send appropriate control signals to the drive and steering servos of the model car.

Each group of about 5 students will build their own mobile robot. At the end of the course a race event will be organized.

The home for the students taking this course is the Mechatronics lab A1507. It is equipped with a phone and some electronic measurement and design equipment such as personal computers, oscilloscopes, digital multimeters soldering irons etc. You have unlimited access to the lab during the project. Simple components will be available in the lab or through our technician. More advanced components must be found and ordered by yourself.

A snapshot of the Mechatronics lab is shown in Figure 1. Each group receives a partly assembled $1 / 10$ scale radio controlled electric car without radio and power electronics for the drive motor. They also receive a microcontroller board developed at our department, a software development system based on MPLAB from Microchip and a $\mathrm{C}$ compiler which runs on a host PC. The PIC-version we use is the PIC16F876. Along with the microcontroller system they also are handed out some self-study material we have developed at our department. The microcontroller system is shown in Figure 2.

\section{Examination}

The course grades are pass or fail. The pass requirements of the Mechatronics course is described like this on the course home page:

To be approved on the course you must do the following:

- Be approved on the lab exercises.

- Participate actively in the project.

- Tidy your workplace in the Mechatronics lab.

- Leave your race car and all items you received from me or our technician at your workplace. 


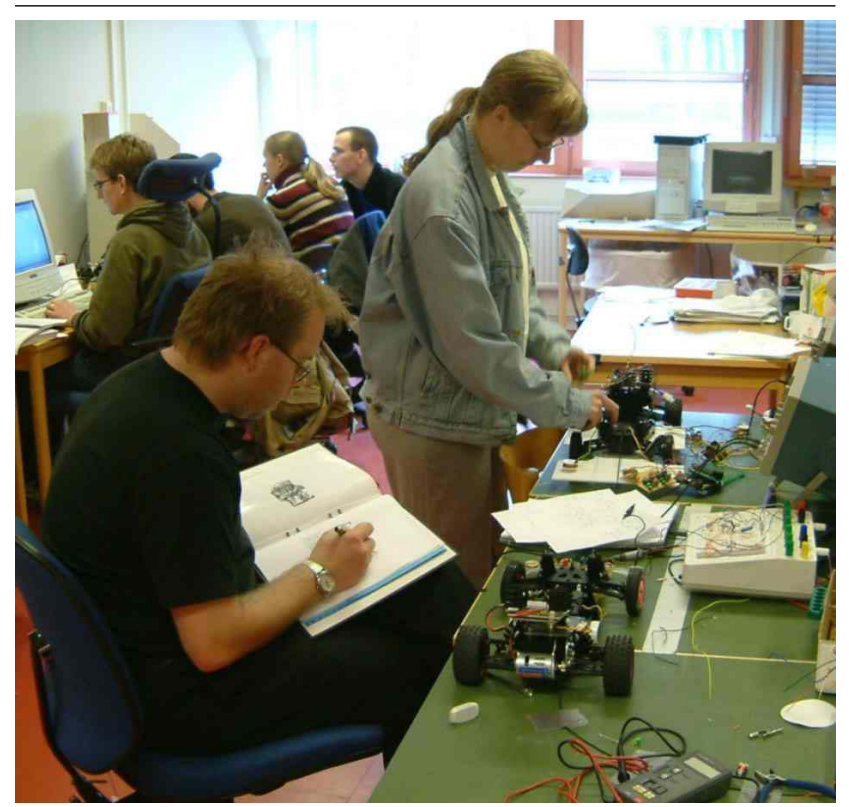

Figure 1. Snapshot from the Mechatronics lab.

- Write a one-page personal report on your own contribution to the project and send it to me. Give some comments on the course in your personal report.

- Write, together with your group, the group report on the project and send it to me.

The group report is required to include a list of the group members estimated contribution to the groups total work. All group members must agree on that list.

\section{The race}

The race track was a closed track of about $50 \mathrm{~m}$ length with both right- and left-hand turns.

\subsection{Rules}

The teams raced against each other two and two in three heats. The team with most victories continued in the race, the other was eliminated. Finally the overall winning team was left.

In each heat one team placed their car on the track at one of the starting points, see Figure 3. The other team placed their car at the other starting point, half-way around the track. Both cars had the same direction around the track. On a signal from the race leader (the author) both cars were released. The one which overtook the other became the heat winner. If one car lost the track completely the other was

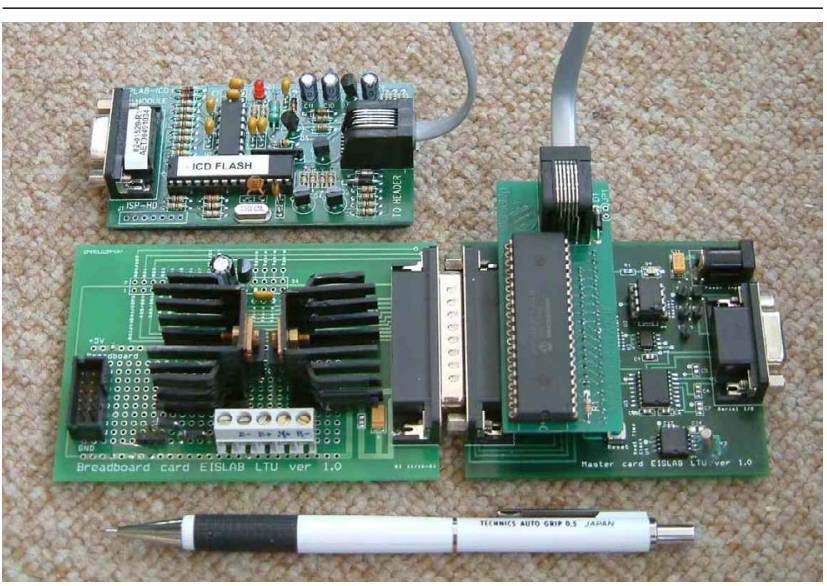

Figure 2. PIC processor board with attached prototype board to the left. Connection to the host PC goes through the RS-232 port on the MPLAB ICD Module in the top of the photo.

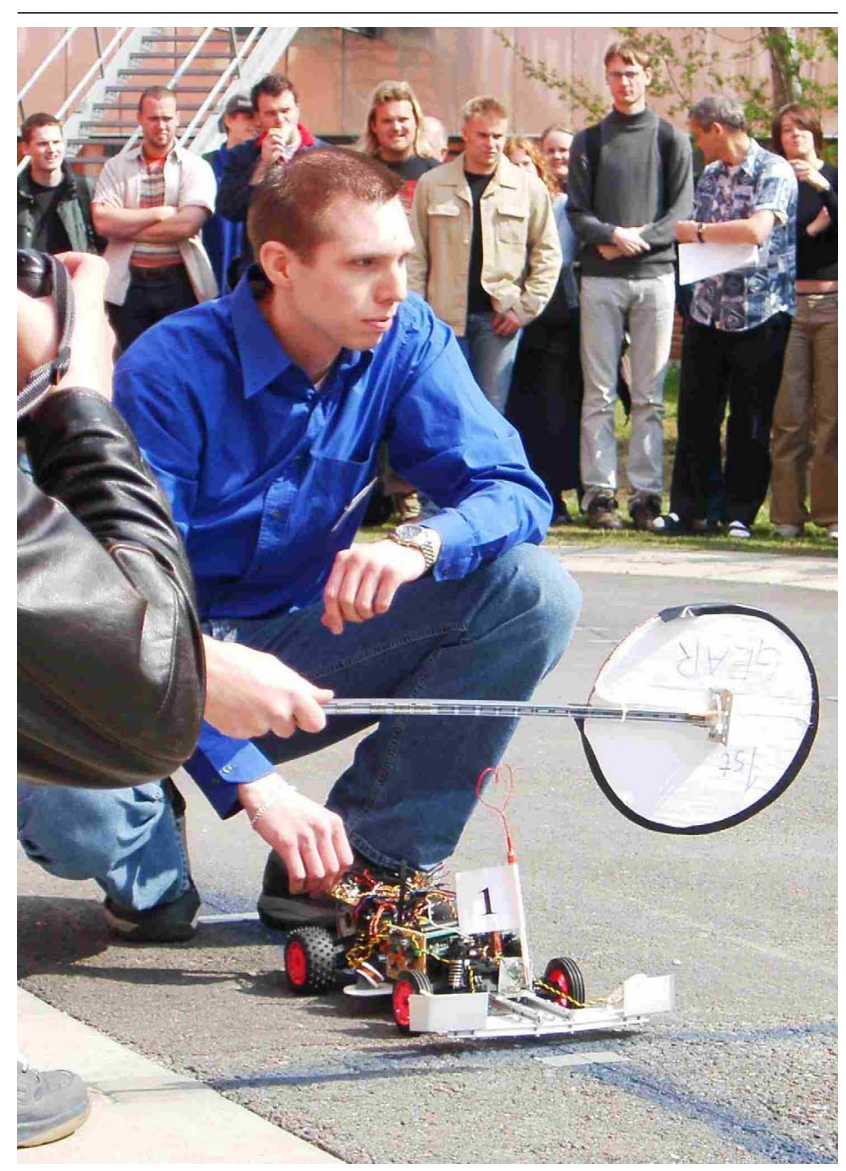

Figure 3. Ready for race! 


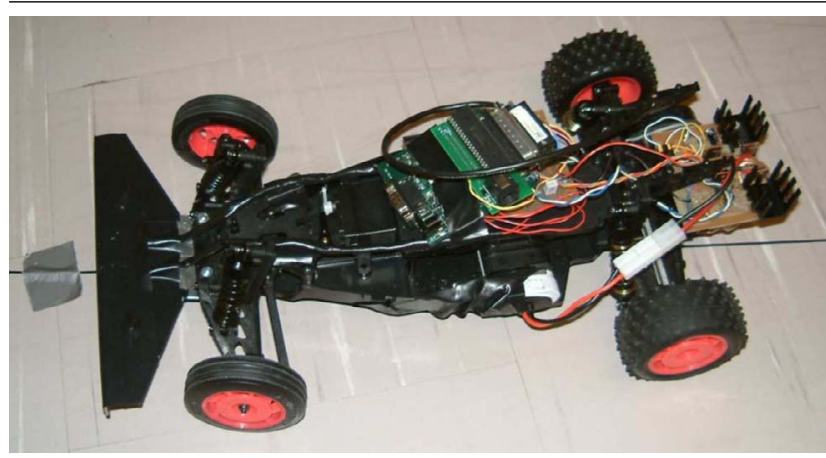

Figure 4. A typical race car. Two sensor coils are placed under the front bumper.

appointed the winner by the race leader. The drive direction was changed between heats.

\subsection{How did it work?}

The race was a success with nice weather and a big enthusiastic crowd. Local media, both newspapers and TV, were present and generated valuable marketing for the Mechatronics course and for Luleå University of Technology.

Most of teams had been working day and night during the last week before the race. All student groups had operational cars at the time of the race. The outcome of the race was fair because the team with the best car did in fact win.

The most important performance factor turned out to be the control algorithm which controlled the steering angle of the car. The controlled process, i.e. to keep the car on the track, is quite complex since it is both non-linear and speed dependent.

\section{Notes on race car designs}

A typical race car is shown in Figure 4. The coolers for the MOS power transistors in the drive motor electronics are visible at the far end of the car. Half of the teams had chosen to use four sensor coils to be able to estimate the angle between the car and the track. Examples are shown in Figures 5 and 6. The winning car, shown in Figure 3, had 4 coils which enabled the team to use a fairly advanced control algorithm for keeping the car on the track.

One team implemented a man-machine interface system in the on-board PIC which enabled them to adjust all control parameters out on the race track when they trimmed the car for optimum performance. The LCD used for output from the PIC is visible in Figure 6. One team member

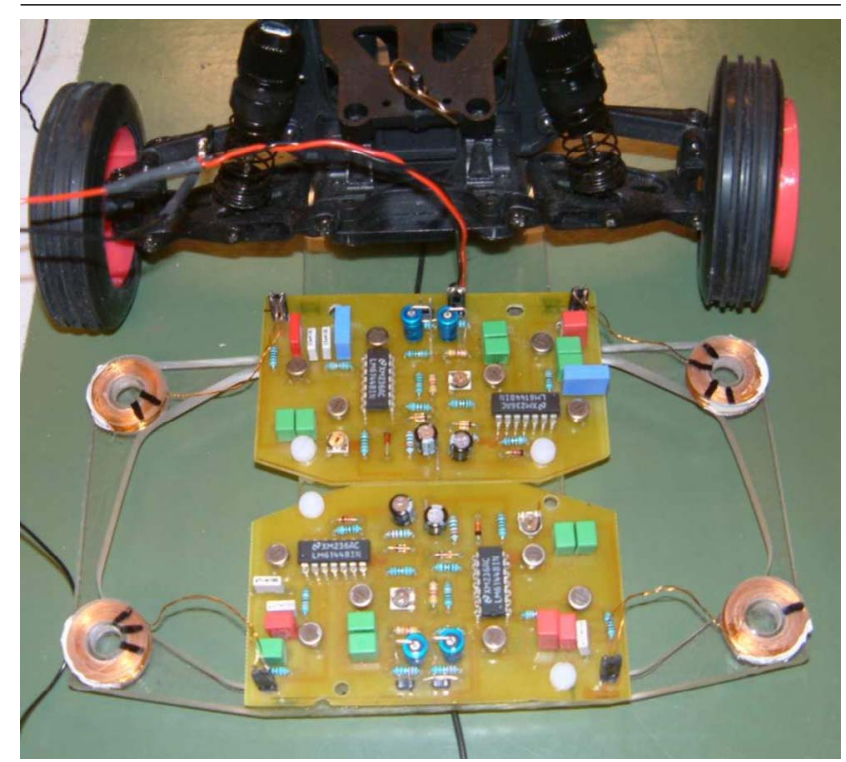

Figure 5. Four sensor coils with electronics.

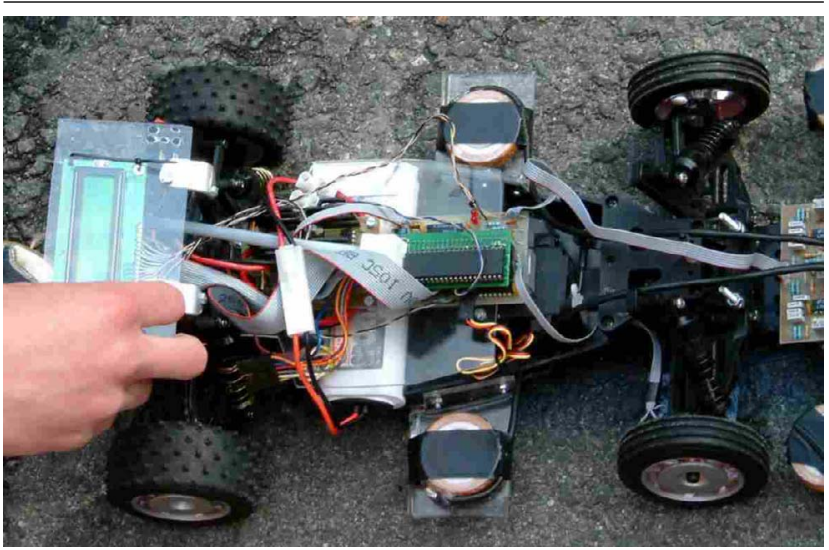

Figure 6. Car with LCD display as part of a simple man-machine interface. This enabled trimming of control parameters out on the track.

is adjusting a parameter value by turning the knob of a potentiometer which is connected to one of the ADC channels in the PIC.

Incremental encoders were built by the teams to be used as sensors for car speed. The teams were given small permanent magnets and Hall sensors chosen by the author. Most of the teams mounted the magnets on one of the gears in the car transmission. An example is shown in Figure 7. Here the magnets are glued to a circular mounting plate which is attached to the gear. 


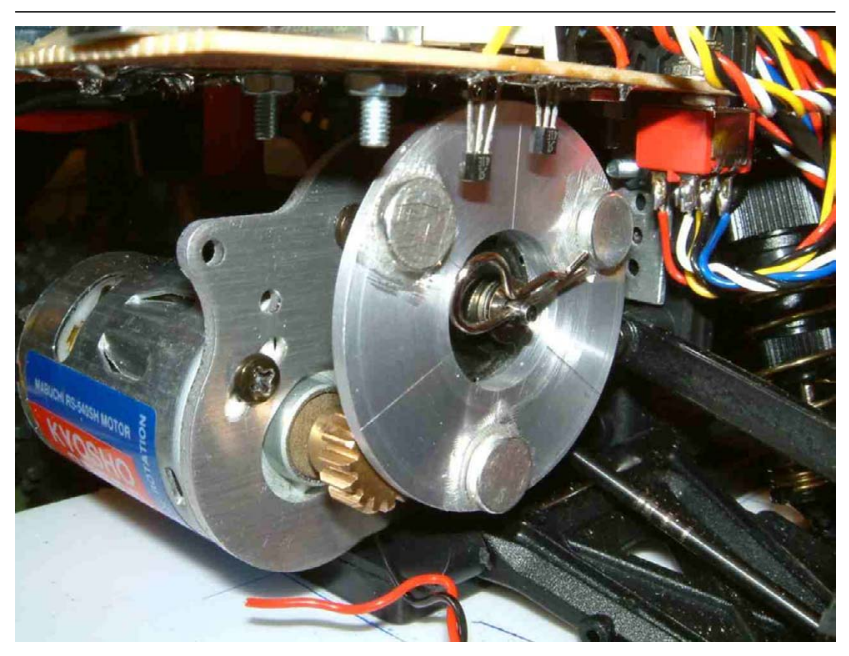

Figure 7. Three permanent magnets mounted to a gear in the transmission and two Hall sensors for speed monitoring.

\section{Student comments}

Almost all students were very satisfied with the course. The following comments are rather typical.

\subsection{Student a}

During the three years I have been studying at this university I have not taken any course which corresponds to the Mechatronics course. It is by far the best and most rewarding course I have taken. It depends to a great deal on the fact that I have not taken any that typical project course where the project is about something sensible.

I have worked more on this course than I normally do and spread my effort more evenly over the quarter. I am surprised over how much time I spent on understanding all details in our design without really needing to do that. The reason was probably the very appealing project.

\subsection{Student b}

I think this is an incredibly interesting and enjoyable course. It has given me the opportunity to use my previous knowledge in a creative way. It is one of my first more practically orientated courses and it is fun to create something useful instead of studying a book and then write an exam. The final part is also fine since it builds up a competition spirit which creates excitement.

- Some negative comments on late delivery of hand-outs for the lab exercises. -
The total impression is however very good. This is one of the best courses I have taken so far and I will warmly recommend it.

\section{Conclusions}

A project with a challenging competition at the end makes students work. Teaching is about inspiring students to work actively with the course curriculum. Only by this kind of effort do they really learn. A fair examination on this kind of project course can be a bit tricky because there will always be a couple of free-riders i.e. students who let the others do the job. The personal reports and the estimated contributions from the group members, given in the group report, were valuable in this respect.

\section{References}

[1] Tyler, R.W. (1949), Basic Principles of Curriculum and Instruction, University of Chicago Press.

[2] Biggs, J. (2003), Teaching for Quality Learning at University, Second Edition, The Society for Research into Higher Education \& Open University Press, ISBN 0-335-21168-2.

[3] http://www.ece.ucdavis.edu/natcar/index.html, (2002).

[4] http://www.robocup.dtu.dk/index.html, (2004).

[5] Rizzoni, G. and Keyhani, A. (1995), Design of Mechatronic Systems: an Integrated Inter-Departmental Curriculum, Mechatronics, Vol. 5, No. 7, pp. 845-853.

[6] Kurfess, S.E. and Witzel, J.G. (2002), Using mechatronics in early design, Mechatronics, Vol. 12, pp. 241-249.

[7] Gardner, J.F. (2002), Two projects for undergraduate mechatronics class: success and failure, Mechatronics, Vol. 12, pp. 337-342.

[8] Hargrove, J.B. (2002), Curriculum, equipment and student project outcomes for mechatronics education in the core mechanical engineering program at Kettering University, Mechatronics, Vol. 12, pp. 343-356.

[9] Carryer, J.E. (2002), March madness: a mechatronics project theme, Mechatronics, Vol. 12, pp. 383-391.

[10] Durfee, W.K. (2003), Mechatronics for the Masses: a Handson Project for a Large, Introductory Design Class, Int. J. Engng. Ed., Vol. 19, pp. 593-596.

[11] Kurfess, S.E., (Guest Editor) (2003), Special Issue on Mechatronics Education, Int. J. Engng. Ed., Vol. 19, pp. 513630.

[12] Durfee, W.K. (1995), Designing Smart Machines: Teaching Mechatronics to Mechanical Engineers through a ProjectBased, Creative Design Course Mechatronics, Vol. 5, No. 7, pp. 775-785.

[13] Lyshevski, S.E. (2002), Mechatronic curriculum - retrorespect and prospect, Mechatronics, Vol. 12, pp. 195-205.

[14] Alciatore, D.G. and Histand, M.B. (2003), Introduction to Mechatronics and Measurement Systems, Second Edition, McGraw-Hill Book Company, ISBN 0-07-119557-2. 